Hydrol. Earth Syst. Sci., 18, 1785-1791, 2014

www.hydrol-earth-syst-sci.net/18/1785/2014/

doi:10.5194/hess-18-1785-2014

(c) Author(s) 2014. CC Attribution 3.0 License.

\title{
Environmental flow assessments in estuaries related to preference of phytoplankton
}

\author{
Z. F. Yang, T. Sun, and R. Zhao \\ State Key Laboratory of Water Environment Simulation, School of Environment, Beijing Normal University, \\ Beijing, 100875, China
}

Correspondence to: Z. F. Yang (zfyang@bnu.edu.cn)

Received: 15 December 2013 - Published in Hydrol. Earth Syst. Sci. Discuss.: 31 January 2014

Revised: - Accepted: 29 March 2014 - Published: 15 May 2014

\begin{abstract}
An approach to assess estuarine environmental flow based on phytoplankton preference, including the complex relationships between hydrological modifications and ecosystem biomass, was developed in this study. We initially established a relationship between biomass requirements for primary and higher nutritional level organisms based on the ecosystem nutritional energy flow principles. Subsequently, diagnostic pigments were employed to represent phytoplankton community biomass, which indicated competition between two groups of phytoplankton in the biochemistry process. Considering empirical relationships between diagnostic pigments and critical environmental factors, biomass responses to river discharge were established by simulating distributions of critical environmental factors under action of river discharges and tide currents. Consequently, environmental flows were recommended for different fish biomass requirements. We used the Yellow River estuary as a case study; and May and June were identified as critical months for maintaining environmental flow. Temporal variation in natural river flow dynamics, which was used as a proxy for environmental flow, should be carefully examined in artificial hydrological regulation strategies, particularly during highamplitude flood pulses, which might result in negative effects on phytoplankton groups, and subsequently higher aquatic species biomass.
\end{abstract}

\section{Introduction}

Estuaries are semi-enclosed coastal transition zones, where freshwater inflow from rivers mixes with tidal action saline water from the sea. Salinity gradients and other unique environmental parameters provide critical habitat for migratory species (Sklar and Browder, 1998). However, variation in freshwater inflow can result in negative or deleterious consequences for many aquatic species by reducing or altering available aquatic habitat (Attrill et al., 1996; Sun et al., 2013). Furthermore, this problem might be exacerbated by climate change (Cai et al., 2011a, b; Sun and Feng, 2013). Environmental flow assessments, which define how much water might be withdrawn from an ecosystem before its capacity to meet social, ecological, and economic needs declines, have become one of the major challenges for sustainable water resource management in estuaries and river basins (Richter et al., 1997; Arthington et al., 2006; Sun et al., 2008, 2009; Yang et al., 2009; Poff et al., 2009).

Successful environmental flow assessments require an accurate understanding of the relationships between flow events and biotic responses (Poff et al., 2009). Studies have established various empirical relationships between ecosystem biomass, communities, and biodiversity, and longterm average river discharges (Arthington et al., 2010; Pasztalenieca and Poniewozik, 2010; Clements et al., 2011). Powell et al. (2002) described a series of relationships between historic monthly inflow, and various fish species catch, which were utilized in the TxEMP model to arrive at an optimized inflow-harvest relationship. Three seagrass species sensitive to salinity changes were selected as indicators to determine the minimum required freshwater inflow for the Caloosahatchee Estuary (Doering et al., 2002). Arhonditsis et al. (2007) examined spatial and temporal patterns in phytoplankton communities to report ecosystem variation influenced by river flow fluctuations in the Neuse River estuary. 
It should be noted any explanation for a relationship between river discharges and biological alterations often remains uncertain due to the complex nature of biological responses to hydrologic changes, which Petts (2009) suggested must be evaluated over a timescale of decades. Accurate long-term flow records and biological distributions are usually unavailable and/or very costly to collect (Alcaázar et al., 2008). Influencing factors are diverse, and the level of food web complexities results in substantial uncertainty in the relationship between hydrologic flow alteration and biological response (Webb et al., 2010). Arthington et al. (2006) argued the absence of data, and an understanding of the relationship between ecological conditions and specific flows, has constrained comprehensive methods for environmental flow assessment.

A complex relationship exists between hydrological modification and biomass in ecosystems, and phytoplankton communities comprise a physical and energetic foundation of ecosystems. Phytoplankton communities can serve as indicator species for ecosystem health assessments (Pasztalenieca and Poniewozik, 2010). Phytoplankton parameters are typically derived from empirical formulas, and experimental data are measured based on the complexity of phytoplankton bioprocesses. Furthermore, ecohydrodynamic models have become more and more sophisticated in characterizing hydrodynamic and biological processes in ecosystems, which often make the approaches impractical (Pastres and Ciavatta, 2005; Gupta et al., 2006; Cai et al., 2009). In recent studies, competition among phytoplankton groups was also examined via biochemical processes (Spitz et al., 2001; Pannard et al., 2008). Investigations into phytoplankton competition mechanisms have become integral to understand the underlying hydrodynamic parameters that influence the compositional shifts in these functional groups.

In the present study, environmental flows were defined by the relationship between phytoplankton community biomass (represented by diagnostic pigments) and environmental factors. Based on the law of energy flow, fish catch, which was derived from phytoplankton community biomass, was used as the primary ecological protection measure for hydrological regulation strategies. In the Yellow River estuary case study, diagnostic pigments represented the phytoplankton community from field data. Recommendations for water resource management in the Yellow River estuary were derived from differences between natural river discharges used as a proxy to determine recommended environmental flows.

\section{Methods}

\subsection{Relationship between river discharge and biomass}

A four-step approach was developed to elucidate the complex relationships between biomass and hydrological changes.
Step 1: based on nutritional requirements for higher biomass species (e.g., fish), the nutritional levels of primary biomass organisms (e.g., phytoplankton) were calculated using the following energy flow equation (Eq. 1):

$A_{\mathrm{p}}=A_{r} / t^{r-1}$,

where $A_{\mathrm{p}}$ is phytoplankton community biomass; $t$ is transference rate between two nutritional levels (10-20\%); and $A_{r}$ is biomass of the $r$ th nutritional level.

Step 2: identify the diagnostic pigments in the phytoplankton community based on estuarine field data.

Step 3: establish empirical relationships between diagnostic pigments and environmental factors at different temporal and spatial scales.

Step 4: define environmental flows based on different species biomass levels by simulating critical environmental factor distributions under river discharge and tidal currents in estuaries.

The relationship between environmental factor distributions and flow regimes was established using a numerical model that simulates spatial and temporal distributions of selected environmental factors as a combined function of river discharge and tidal currents. The depth-integrated equations for conservation of motion and water are

$$
\begin{aligned}
& \frac{\partial \zeta}{\partial t}+\frac{\partial}{\partial x}(H u)+\frac{\partial}{\partial y}(H v)=0 \\
& \frac{\partial u}{\partial t}+\frac{\partial u u}{\partial x}+\frac{\partial v u}{\partial y}=f v+g \frac{\partial \zeta}{\partial x}+g \frac{u \sqrt{u^{2}+v^{2}}}{H C^{2}} \\
& +\frac{\partial}{\partial x}\left(\varepsilon \frac{\partial u}{\partial x}\right)+\frac{\partial}{\partial y}\left(\varepsilon \frac{\partial u}{\partial y}\right) \\
& \frac{\partial v}{\partial t}+\frac{\partial u v}{\partial x}+\frac{\partial v v}{\partial y}=f u+g \frac{\partial \zeta}{\partial y}+g \frac{v \sqrt{u^{2}+v^{2}}}{H C^{2}} \\
& +\frac{\partial}{\partial x}\left(\varepsilon \frac{\partial v}{\partial x}\right)+\frac{\partial}{\partial y}\left(\varepsilon \frac{\partial v}{\partial y}\right),
\end{aligned}
$$

where $t(\mathrm{~s})$ is time; $u$ and $v$ are current velocities $\left(\mathrm{m} \mathrm{s}^{-1}\right)$ in $x$ and $y$ directions, respectively; $f$ is the Coriolis factor; $C$ is the Chézy coefficient $\left(\mathrm{m}^{1 / 2} \mathrm{~s}^{-1}\right) ; H$ is total water depth (m) from water surface to bottom $(H=\zeta+d$, where $d$ is local water depth $(\mathrm{m})$ measured from mean water level to bottom, and $\zeta$ is water surface elevation (m) measured upwards from mean water level); $g$ is gravitational acceleration $\left(\mathrm{m} \mathrm{s}^{-2}\right)$; and $\varepsilon$ is a dispersion coefficient $\left(\mathrm{m}^{2} \mathrm{~s}^{-1}\right)$.

The two-dimensional convection-diffusion equation integrated over water depth, which assumes vertical mixing, is written as

$$
\begin{aligned}
\frac{\partial(H S)}{\partial t} & +\frac{\partial(H u S)}{\partial x}+\frac{\partial(H v S)}{\partial y}=\frac{\partial}{\partial x}\left(K_{x x} H \frac{\partial S}{\partial x}\right) \\
& +\frac{\partial}{\partial x}\left(K_{x y} H \frac{\partial S}{\partial y}\right)+\frac{\partial}{\partial y}\left(K_{y x} H \frac{\partial S}{\partial x}\right) \\
& +\frac{\partial}{\partial y}\left(K_{y y} H \frac{\partial S}{\partial y}\right)+S_{m},
\end{aligned}
$$


Table 1. Ecological measures in the Yellow River estuary (diagnostic pigments).

\begin{tabular}{llllllll}
\hline & \multicolumn{3}{c}{ Spring } & & \multicolumn{2}{c}{ Autumn } \\
\cline { 2 - 3 } & Maximum & Medium & \multirow{2}{*}{ Minimum } & & Maximum & Medium & \multicolumn{2}{c}{ Minimum } \\
\hline Fish biomass & $5006.5-526.2$ & $311.5-56.5$ & $78.6-13.9$ & & $965.3-128.1$ & $345.1-58.8$ & $254.3-45.3$ \\
Chlorophyll $a\left(10^{-3} \mathrm{mg} \mathrm{L}^{-1}\right)$ & $12.36-1.30$ & $0.77-0.14$ & $0.19-0.03$ & & $2.38-0.32$ & $0.85-0.15$ & $0.63-0.11$ \\
Fucoxanthin (logarithm values) & $1.83-0.19$ & $-0.19-1.43$ & $-1.19-2.45$ & & $0.71-0.94$ & $-0.13-1.58$ & $-0.38-1.79$ \\
Peridinin (logarithm values) & $0.699-0.07$ & $-0.073-0.55$ & $-0.46-0.94$ & & $0.15-0.20$ & $-0.028-0.34$ & $-0.081-0.38$ \\
Salinity & $16.9-19.2$ & $22.1-22.3$ & $25.4-27.2$ & & $4.2-7.7$ & $8.8-12.6$ & $17.5-19.3$ \\
\hline
\end{tabular}

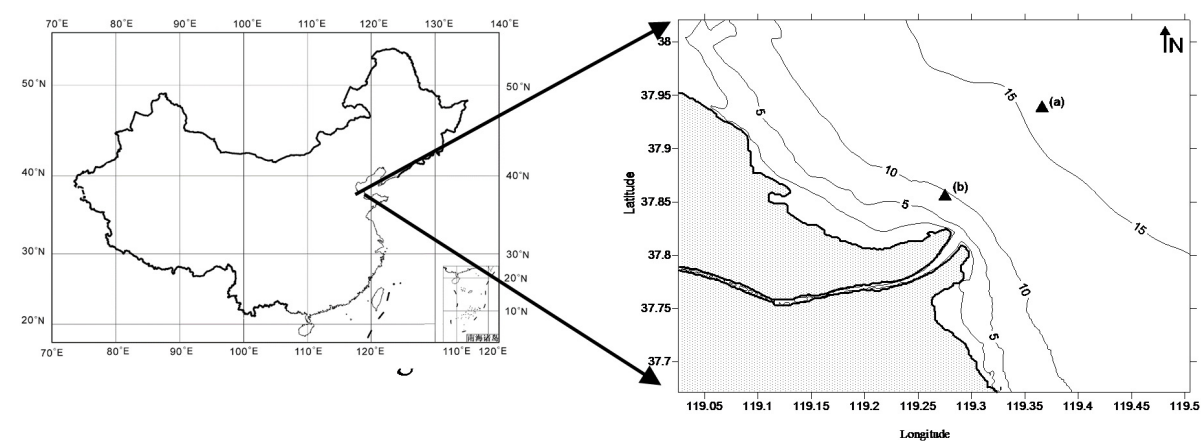

Fig. 1. Yellow River estuary in China.

where $S$ is the concentration of dissolved solutes (unit/volume); $S_{m}$, a source term; and $K$, the depthaveraged dispersion-diffusion coefficient $\left(\mathrm{m}^{2} \mathrm{~s}^{-1}\right)$ for orientations $x$ and $y$.

\subsection{Temporal variability in environmental flows}

Due to the close relationships between hydrological and biological processes in ecosystems, temporal changes in natural river discharge were selected as indicators of temporal variation in environmental flow (Sun et al., 2013).

$R_{i}=\sum_{j=1}^{n} W_{j i} / \sum_{j=1}^{n} W_{j}$,

where $R_{i}$ is the ratio (\%) of monthly (or daily) river discharge in month $i$ (or day $i$ ) to the annual discharge; $W_{j}$, is the annual river discharge $\left(\mathrm{m}^{3}\right)$ in year $j$; and $W_{j i}$ is the river discharge $\left(\mathrm{m}^{3}\right)$ in month $i$ (or day $i$ ) of year $j$.

Following integration of ecosystem protection measures for a particular season crucial to reproduction, survival, and/or growth of a target species, this process can also quantify environmental flows that meet hydrological strategies for other seasons.

\section{Study area}

The Yellow River is China's second largest river. Although it supports only $2 \%$ of the country's water resources, the river supplies $12 \%$ of the population with water and irrigates
$19 \%$ of the farmland. The gap between water availability and demand has been increasing with social and economic development in regions along the Yellow River. The Yellow River estuary is located in eastern Shandong province, west of the Bohai Sea (Fig. 1). The frequency of complete drying or ephemeral flow in the downstream of the river has been rising consistently since the early 1970s. Shortages in freshwater inflow results in severe ecosystem deterioration, including wetland loss, increasing soil salinization, decreasing vegetation surface area, and decreasing fish (by $40 \%$ ) and bird (by $30 \%$ ) populations in the estuary. In the Yellow River estuary and the Bohai Sea, species number, density, and biomass dropped by $38.7,35.5$, and $46.0 \%$, respectively, from 1982/1983 to 1992/1993 (Zhu and Tang, 2002; Fan and Huang, 2008). In addition, nutritional level of fish in the Yellow River estuary decreased from 4.1 to 3.4 over this period (Zhang, 2005).

Phytoplankton communities were selected as bioindicators of estuarine ecosystem health, and diagnostic pigments were chosen to characterize the phytoplankton community. The dominant phytoplankton groups in the Yellow River estuary were diatoms (about $75 \%$ ) and dinoflagellates (about $15 \%$ ). These two phytoplankton groups were represented by the diagnostic pigments fucoxanthin and Peridinin. Phytoplankton community biomass was determined using the energy flow equation (Eq. 1) based on the fish catches from different decades (Table 1). 

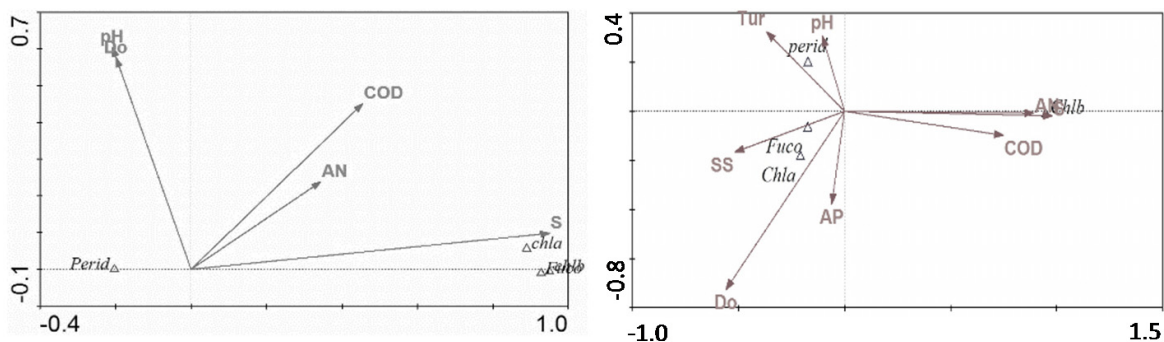

(Spring)
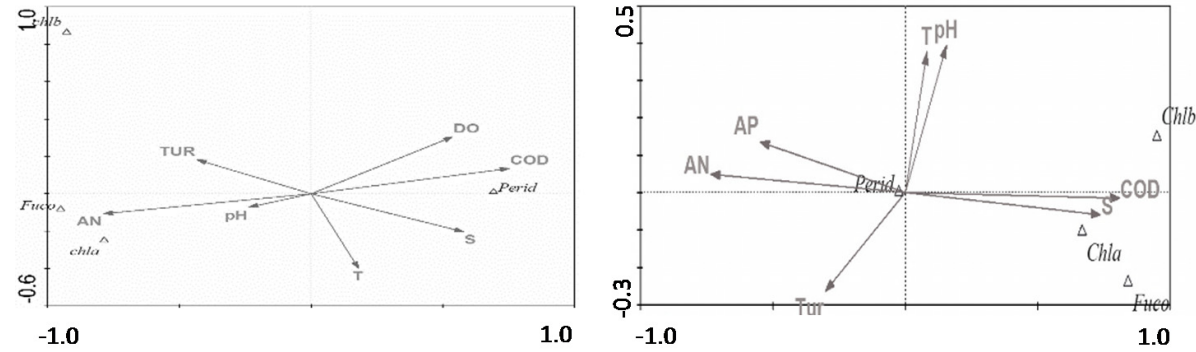

(Autumn)

Fig. 2. CCA plots of diagnostic pigments and environmental factors in (a) spring and (b) autumn.

\section{Results and discussion}

Canonical correspondence analysis (CCA) was used to illustrate the relationships between diagnostic pigments and different environmental variables under different seasons based on field data. The results served to identify the most important environmental factors that influenced phytoplankton community diagnostic pigments. CCA plots show environmental factors identified by lines with arrows (Fig. 2). Line length indicates the relationship between environmental variable and diagnostic pigment. Angles between lines and axes indicate the degree of correlation, with small angles indicating a higher correlation. CCA identified salinity as the most influential environmental factor affecting diagnostic pigments, and empirical relationships between salinity and diagnostic pigments were determined based on these observed results.

The numerical model for salinity and water depth distributions with changes in river discharge and tidal current was validated with the hydrographic data (Sun et al., 2012). Relationships among varied freshwater inflow levels and salinity distribution in critical habitats were established in the Yellow River estuary based on the validated numerical model. Furthermore, diagnostic pigment attributes were applied as ecological determinants (Table 1), and the threshold value of environmental flow rate can be determined for critical estuarine seasons (Fig. 3).

Temporal variation in natural river discharge was used as a proxy for annual environmental flow, obtained using Eq. (6). The maximum, medium, and minimum annual environmental flows for critical habitats were $452.4-476.9 \times 10^{8} \mathrm{~m}^{3}, \quad 280.2-291.4 \times 10^{8} \mathrm{~m}^{3}$, and
136.4-139.4 $\times 10^{8} \mathrm{~m}^{3}$, respectively, which represent 84.6$89.1,52.4-54.5$, and $25.5-26.1 \%$ of the natural runoff.

Comparisons among different calculated environmental flow levels, and 1950 to 2000 recorded river discharges indicated that in $87 \%(n=43)$ of the years examined, annual river discharge was above minimum environmental flows; in $57 \%(n=28)$, discharge was greater than medium environmental flows; and in $29 \%(n=14)$ of the years examined, annual river discharge was greater than maximum environmental flows. Environmental flows were not met after the 1980 s, and showed increased reductions in the 1990s. On average from 1955 to 2000, the actual natural river discharge levels did not satisfy the medium environmental flows from February to July, and even the minimum requirements in June (Fig. 4).

A comparison between monthly environmental flow and river discharge during wet, average, and dry years is shown in Fig. 5. From March to May, the environmental flows were mainly influenced by anthropogenic activities. As a result, monthly river discharge did not satisfy minimum environmental flows in May and June, even during the wet year (1966). During these 2 months, we recommend close regulation of river flow discharge, which are critical months for fish reproduction and growth. Because we are using natural river discharge as a proxy for environmental flow, it is necessary to adjust temporal variation in river discharge to fulfill temporal variation in environmental flow.

Water-sediment regulation was initiated for the Yellow River in 2000. During the regulation, maximum inflow rate at Lijin station reached $2500-3000 \mathrm{~m}^{3} \mathrm{~s}^{-1}$. High inflow rates might change the distribution of environmental factors in the Yellow River estuary, and subsequently 

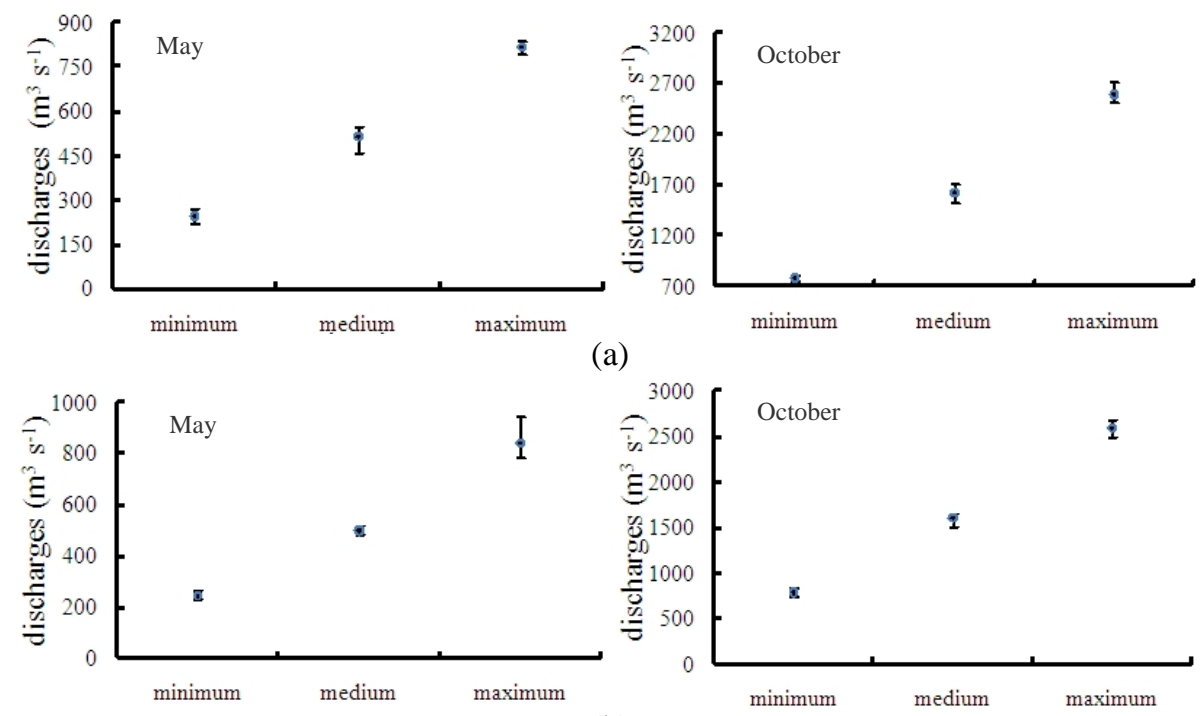

(a)

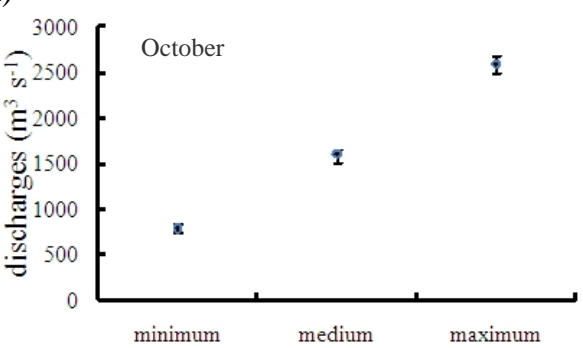

(b)

Fig. 3. Environmental flow for critical habitats in different seasons (spring and autumn) for (a) Habitat a; and (b) Habitat b shown in Fig. 1.

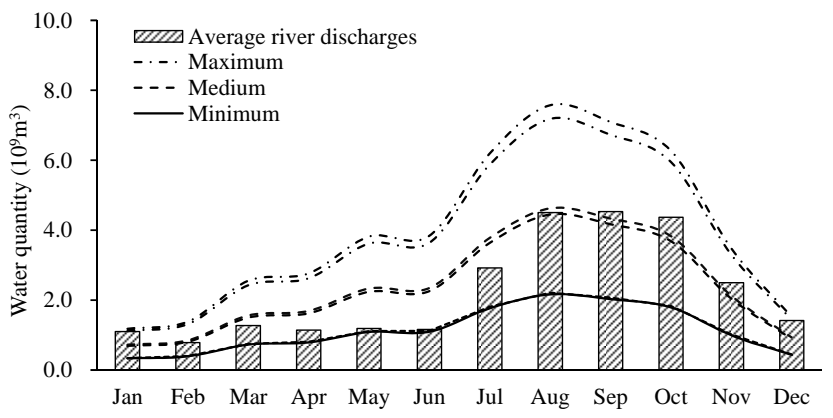

Fig. 4. Temporal variation in environmental flow and average natural river discharge.

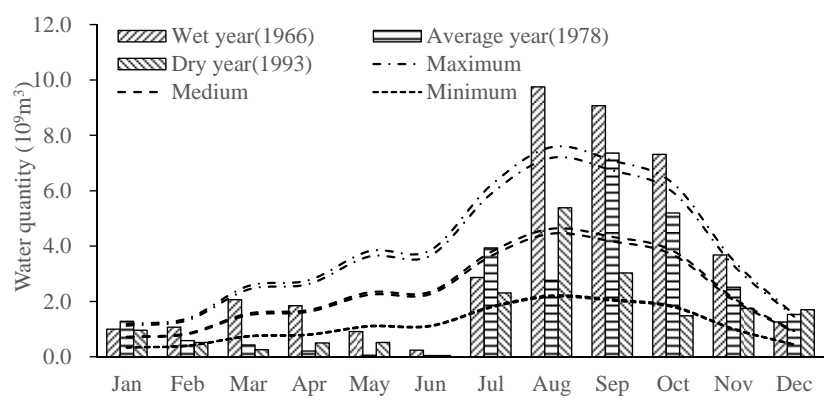

Fig. 5. Monthly environmental flow and natural river discharge in wet (1966), average (1978), and dry years (1993).

phytoplankton spatial distribution. Therefore, the influence of water-sediment regulation on threshold values, as well as the temporal variation in environmental flow, must be investigated on the basis of phytoplankton community characteristics. For example, in July 2002, ammonia nitrogen

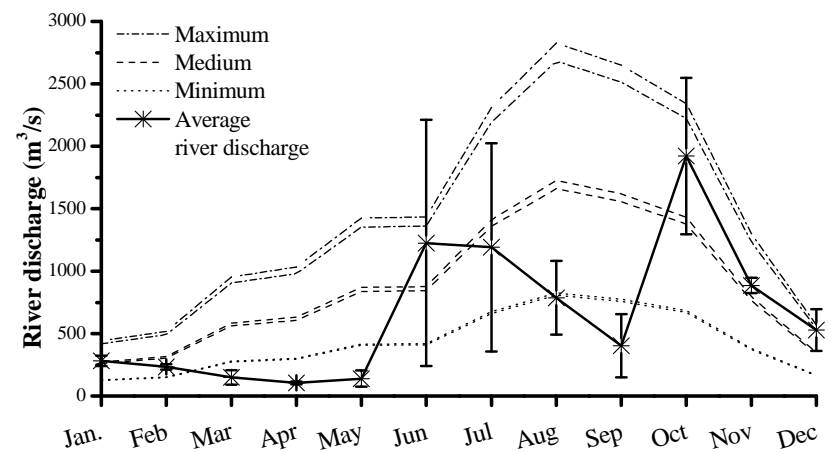

Fig. 6. Variation in natural river discharge (2005) and environmental flow in the Yellow River estuary.

concentration in the Yellow River estuary decreased rapidly when regulation was initiated, and subsequently reached the lowest observed values before exhibiting slight increases following completion of river regulation protocols (Wang, 2007).

Daily discharge measures from 2005 compared with environmental flow indicated that, during the regulation period, daily discharge could not meet minimum environmental flow level before water-sediment regulation in June (Fig. 6). During regulation, notable increased discharge occurred, which exceeded maximum levels, and subsequently exhibited rapid decreases thereafter. Following regulation, discharge flow rates were lower than minimum levels. Compatibility with environmental flows in estuarine habitats should also be considered when regulating flow. Discrepancies between discharge (approximately $3000 \mathrm{~m}^{3} \mathrm{~s}^{-1}$ ) and environmental flow are particularly high in June and September. 


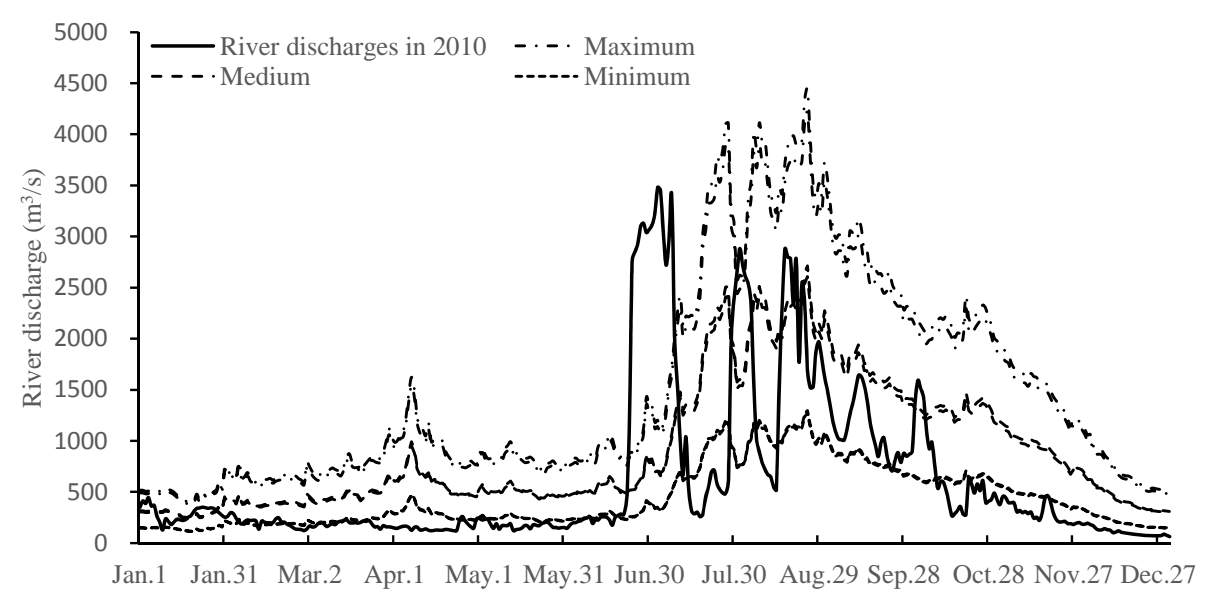

Fig. 7. Daily discharge comparisons during water-sediment regulation, and daily environmental flow in the Yellow River estuary.

Monthly river discharge recorded in 2010 and environmental flow in the estuary were compared (Fig. 7). Results showed that if regulation was conducted in July or August, discharge would fall below maximum environmental flow, and peak discharge might not adversely affect the estuarine ecosystem. In comparison, intensive discharge regulation in June would substantially change natural river dynamics, and might adversely affect the health and stability of the estuarine ecosystem.

High river discharge can reduce phytoplankton biomass and impact ecosystem stability. Water-sediment regulation in June is not compatible with natural discharge patterns, which did not satisfy habitat environmental flow rate. Controlling the timing and intensity of peak discharge during artificial hydrological regulation can reduce the losses in fishery resources.

\section{Conclusions}

Here, we developed an approach to estimate estuarine environmental flows for different fish biomass requirements associated with phytoplankton preference. Phytoplankton community biomass was represented by diagnostic pigments to indicate competition between phytoplankton groups in biochemical processes. Diatoms and dinoflagellates, represented by fucoxanthin and peridinin diagnostic pigments, were identified as the dominant phytoplankton groups in the Yellow River estuary. Environmental flow threshold values in the Yellow River estuary were determined based on the relationship between ecological and hydrological processes. Maximum, medium, and minimum annual environmental flows in the Yellow River estuary were responsible for 84.6-89.1, 52.4-54.5, and 25.5-26.1\% of the natural runoff, respectively. May and June were identified as critical months. Artificial hydrological regulation strategies should carefully consider temporal variation in natural river flow dynamics. This is particularly important because high-amplitude flood pulses might cause negative effects on phytoplankton groups, and subsequently higher organism biomass.

Acknowledgements. This work was supported by the National Science Foundation for Innovative Research Group (no. 51121003), the National Basic Research Program of China (973) (no. 2013CB430402), and International Science \& Technology Cooperation Program of China (no. 2011DFA72420).

Edited by: Y. Cai

\section{References}

Alcázar, J., Palau, A., and Vega-García, C.: A neural net model for environmental flow estimation at the Ebro River Basin, Spain, J. Hydrol., 349, 44-45, 2008.

Arhonditsis, G. B., Stow, C. A., Paerl, H. W., Valdes-Weaver, L. M., Steinberg, L. J., and Reckhow, K. H.: Delineation of the role of nutrient dynamics and hydrologic forcing on phytoplankton patterns along a freshwater-marine continuum, Ecol. Model., 208, 230-246, 2007.

Arthington, A. H., Bunn, S. E., Poff, N. L., and Naiman, R. J.: The Challenge of Providing Environmental Flow Rules to Sustain River Ecosystems, Ecol. Appl., 16, 1311-1318, 2006.

Arthington, A. H., Naiman, R. J., McClain, M. E., and Nilsson, C.: Preserving the biodiversity and ecological services of rivers: new challenges and research opportunities, Freshwater Biol., 55, 1$16,2010$.

Attrill, M. J., Rundle, S. D., and Thomas, R. M.: The influence of drought-induced low freshwater flow on an upper-estuarine macroinvertebrate community, Water Res., 30, 261-268, 1996.

Cai, Y. P., Huang, G. H., Yang, Z. F., and Tian, Q.: Identification of optimal strategies for energy management systems planning under multiple uncertainties, Appl. Energy, 86, 480-495, 2009.

Cai, Y. P., Huang, G. H., Tan, Q., and Chen, B.: Identification of optimal strategies for improving eco-resilience to floods in ecologically vulnerable regions of a wetland, Ecol. Model., 222, 360369, 2011 a. 
Cai, Y. P., Huang, G. H., Tan, Q., and Yang, Z. F.: An integrated approach for climate-change impact analysis and adaptation planning under multi-level uncertainties, Part I: Methodology, Renew. Sust. Energy. Rev., 15, 2779-2790, 2011b.

Clements, W. H., Arnold, J. L., Koel, T. M., Daley, R., and Jean, C.: Responses of benthic macroinvertebrate communities to natural geothermal discharges in Yellowstone National Park, USA, Aquat. Ecol., 45, 137-149, 2011.

Doering, P. H., Chamberlain, R. H., and Haunert, D. E.: Using submerged aquatic vegetation to establish minimum and maximum freshwater inflows to the Caloosahatchie Estuary, Florida, Estuaries, 25, 1343-1354, 2002.

Fan, H. and Huang, H. J.: Response of coastal marine ecoenvironment to river fluxes into the sea: A case study of the Huanghe (Yellow) River mouth and adjacent waters, Mar. Environ. Res., 65, 378-387, 2008.

Gupta, I., Dhage, S., Jacob, N., Navada, S. V., and Kumar, R.: Calibration and validation of far field dilution models for outfall Atworli, Mumbai, Environ. Monit. Assess., 114, 199-209, 2006.

Pannard, A., Claquin, P., Klein, C., Le Roy, B., and Véron, B.: Short-term variability of the phytoplankton community in coastal ecosystem in response to physical and chemical conditions' changes, Estuar. Coast. Shelf S., 80, 212-224, 2008.

Pastres, R., and Ciavatta, S.: A comparison between the uncertainties in model parameters and in forcing functions: its application to a 3D water-quality model, Environ. Modell. Softw., 20, 981989, 2005

Pasztalenieca, A. and Poniewozik, M.: Phytoplankton based assessment of the ecological status of four shallow lakes (Eastern Poland) according to Water Framework Directive - a comparison of approaches, Limnologica, 40, 251-259, 2010.

Petts, G. E.: Instream flow science for sustainable river management, J. Am. Water Resour. A., 45, 1071-1086, 2009.

Poff, N. L., Richter, B. D., Arthington, A. H., Bunn, S. E., Naiman, R. J., Kendy, E., Acreman, M., Apse, C., Bledsoe, B. P., Freeman, M. C., Henriksen, J., Jacobson, R. B., Kennen, J. G., Merritt, D. M., O'Keeffe, J. H., Olden, J. D., Rogers, K., Tharme, R. E., and Warner, A.: The ecological limits of hydrologic alteration (ELOHA): a new framework for developing regional environmental flow standards, Freshwater Biol., 55, 147-170, 2009.

Powell, G. L., Matsumoto, J., and Brock, D. A.: Methods for determining minimum freshwater inflow needs of Texas Bays and estuaries, Estuaries 25, 1262-1274, 2002.
Richter, B. D., Baumgartner, J. V., Wigington, R., and Braun, D. P.: How much water does a river need?, Freshwater Biol., 37, $231-$ 249, 1997.

Sklar, F. H. and Browder, J. A.: Coastal environmental impacts brought about by alterations to freshwater inflow in the Gulf of Mexico, Environ. Manage., 22, 547-562, 1998.

Spitz, Y. H., Moisan, J. R., and Abbott, M. R.: Configuring an ecosystem model using data from the Bermuda Atlantic Time Series (BATS), Deep-Sea Res. Pt. II, 48, 1733-1768, 2001.

Sun, T. and Feng, M. L.: Multistage analysis of hydrologic alterations in the Yellow River, China, River Res. Appl., 29, 9911003, 2013.

Sun, T., Yang, Z. F., and Cui, B. S.: Critical environmental flows to support integrated ecological objectives for the Yellow River Estuary, China, Water Resour. Manage., 22, 973-989, 2008.

Sun, T., Yang, Z. F., Shen, Z. Y., and Zhao, R.: Environmental flows for the Yangtze Estuary based on salinity objectives, Commun. Nonlin. Sci., 14, 959-971, 2009.

Sun, T., Xu, J., and Yang, Z. F.: Objective-based Method for Environmental Flow Assessment in Estuaries and Its Application to the Yellow River Estuary, China, Estuar. Coast., 35, 892-903, 2012.

Sun, T., Xu, J., and Yang, Z. F.: Environmental flow assessments in estuaries based on an integrated multi-objective method, Hydrol. Earth Syst. Sci., 17, 751-760, doi:10.5194/hess-17-751-2013, 2013.

Wang, T.: The variation of nutrients in the lower main chnnel of the Yellow River from 2002 to 2004 and Water-sediment regulation, China Ocean University, Qingdao, Shandong, 2007.

Webb, J. A., Stewardson, M. J., and Koster, W. M.: Detecting ecological responses to flow variation using Bayesian hierarchical models, Freshwater Biol., 55, 108-126, 2010.

Yang, Z. F., Sun, T., Cui, B. S., Chen, B., and Chen, G. Q.: Environmental flow requirements for integrated water resources allocation in the Yellow River Basin, China, Commun. Nonlin. Sci., 14, 2469-2481, 2009.

Zhang, B.: Preliminary Studies on Marine Food Web and Trophodynamics in China Coastal Seas, China Ocean University, Qingdao, Shandong, 2005.

Zhu, X. and Tang, Q.: Structuring dominant components within fish community in Bohai Sea system, Studia Marina Sinica, 44, 159_ $168,2002$. 